\title{
Efektivitas Aplikasi Tumbuh Kembang Balita Usia 9-60 bulan
}

\section{Effectiveness Of App Of Growth And Development Toddlers Age 9-60 Months}

\author{
Nilatul Izah ${ }^{1}$, Muhaamad Bakhar, Umi Baroroh \\ ${ }^{1,3}$ Prodi DIII Kebidanan Politeknik Harapan Bersama \\ ${ }^{2}$ Prodi DIII TeknikKomputer Politeknik Harapan Bersama \\ Email: nilaizah12@gmail.com
}

\begin{abstract}
ABSTRAK
Deteksi dini tumbuh kembang merupakan kegiatan atau pemeriksaan untuk menemukan secara dini adanya penyimpangan tumbuh kembang agar lebih mudah dilakukan penanganan selanjutnya atau diintervensi. Metode stimulasi yang dilakukan selama ini masih mengandalkan tenaga kesehatan yang dilakukan sebulan sekali diposyandu. Peneliti sebelumnya telah membuat "aplikasi stimulasi tumbuh kembang balita" yang terdapat di smartphone yang diharapkan berfungsi sebagai panduan orangtua melakukan stimulasi terhadap anaknya. Penelitian ini bertujuan untuk menganalisis efektivitas (Isi, Bentuk, Kemudahan Penggunaan, Keakuratan, Ketepatan Waktu) aplikasi tumbuh kembang balita. Jenis penelitian ini yaitu kuantitatif dengan desain pre eksperimen one grouppre post design. Analisis bivariat dalam penelitian ini digunakan untuk menganalisis perbedaan antara sebelum dan setelah menggunakan aplikasi tumbuh kembang balita. Uji Chi Kuadrat digunakan untuk menganalisis bivariat. Hasil penelitian menunjukkan bahwa penggunaan aplikasi tumbuh kembang balita terdapat keefektivan pada ketiga dimensi yaitu dari segi bentuk, kemudahan penggunaan dan ketepatan waktu. Hasil analisis bentuk didapatkan nilai $\mathrm{p}=0,000$, kemudahan penggunaan didapatkan nilai $\mathrm{p}=0,014$ dan ketepatan waktu didapatkan nilai $\mathrm{p}=$ 0,002. Penggunaan aplikasi tumbuh kembang balita tidak efektif dari segi isi dan keakuratan dimana dari hasil analisis uji Chi Kuadrat segi keakuratan diperoleh nilai-p sebesar 0,432 dan segi isi diperoleh nilai $p$ $=0,122$.
\end{abstract}

Kata Kunci: Efektivitas, Aplikasi, Tumbuh Kembang

\begin{abstract}
Early detection of growth and development is an activity or examination to find early growth and development deviations to make it easier to do further handling or intervention. The method of stimulation carried out so far still relies on health workers being conducted once a month at the posyandu. Previous researchers have made "toddler growth stimulation applications" contained in smartphones that are expected to function as a guide for parents to stimulate their children. This study aims to analyze the effectiveness (Content, Form, Ease of Use, Accuracy, Timeliness) of toddlers' growth and development applications. This type of research is quantitative with one group pre post experimental design. Bivariate analysis in this study was used to analyze the differences between before and after using the toddler growth and development application. Chi Square Test is used to analyze bivariate. The results showed that the use of toddler growth and development applications have effectiveness in all three dimensions, namely in terms of shape, ease of use and timeliness. The results of the analysis of the form obtained $p=0,000$, ease of use obtained $p=0.014$ and timeliness obtained $p=0.002$. The use of toddler growth and development applications is not effective in terms of content and accuracy where from the Chi Square test results in terms of accuracy obtained p-value of 0.432 and in terms of content obtained p value $=0.122$
\end{abstract}

Keywords: Effectiveness, Application, Growth and Development 


\section{PENDAHULUAN}

Pembangunan kesehatan untuk tahun 2015 - 2019 berfokus pada empat program utama yaitu menurunkan jumlah kematian ibu (AKI) dan bayi (AKB), menurunkan kejadian balita pendek (stunting), mengendalikan kasus penyakit menular dan tidak menular. Indonesia termasuk negara yang mempunyai tiga masalah prioritas gizi yaitu pendek, lemah dan obesitas pada balita, hal ini ditunjukkan oleh Global Nutrition Report pada tahun 2014 (Kemenkes RI, 2016).

Pertumbuhan didefinisikan sebagai perubahan jumlah dan besar sel yang semakin bertambah dan dapat diukur, sedangkan perkembangan adalah semakin sempurnanya kemampuan alat tubuh yang dapat dicapai melalui kematangan dan belajar (Alimul, 2005).

Perkembangan anak baik kemampuan kreativitas, kesadaran sosial, emosional serta intelegensia sangat dipengaruhi oleh periode tumbuh kembang anak pada masa balita merupakan pertumbuhan dasar yang merupakan landasan perkembangan berikutnya.

Memantau tumbuh kembang balita dapat dilakukan diposyandu, hal tersebut merupakan upaya yang sangat strategis untuk mendeteksi dini terjadinya gangguan pertumbuhan dan perkembangan. Usia bayi $0-9$ bulan masih mendapatkan imuniasi dasar lengkap, sehingga memungkinkan ibu akan membawa bayinya ke posyandu atau pelayanan kesehatan lainnya. Ketika bayi sudah melewati masa usia 9 bulan tidak menutup kemungkinan ibu tidak membawa kembali anaknya ke pelayanan kesehatan kecuali jika anak mengalami sakit atau masalah kesehatan lainnya (Arif, 2010).

Keterampilan dan peran ibu sangat bermanfaat bagi proses pertumbuhan serta perkembangan anak secara menyeluruh sehingga orang tua dapat segera mengetahu proses perkembangan anaknya dan dapat memberikan stimulasi tumbuh kembang anak dalam berbagai aspek baik fisik, mental maupun sosial. Stimulasi merupakan usaha melakukan perangsangan yang berasal dari lingkungan atau diluar individu anak. Orang tua sangat perlu memperhatikan pertumbuhan dan perkebangan anak, terutama seorang ibu. Pertumbuhan dan perkembangan anak tidak akan maksimal tanpa arahan dan pendampingan dari orang tuanya. (Soetjiningsih, 1995).

"Deteksi dini tumbuh kembang dilakukan dengan tujuan untuk 
mendapatkan secara awal/dini Tumbuh kembang anak sangat penyimpangan pertumbuhan dan dipengeruhi oleh lingkungan dan perkembangan agar lebih mudah interaksi antara anak dengan orangtua. dilakukan penanganan selanjutnya atau Tujuan utamanya untuk mempertahankan diintervensi" (Arif, 2010).

Salahsatu periode terpenting dalam proses perkembangan anak yaitu pada periode balita, yang merupakan pertumbuhan dasar yang akan mempengaruhi dan menentukan perkembangan anak selanjutnya. Proses tumbuh kembang terbagi dalam beberapa tahapan usia, salah satunya usia 36-48 bulan disebut sebagai usia prasekolah. Masa yang sangat penting karena anak akan mampu menyesuaikan dirinya dengan lingkungan dan masa yang sensitif terjadinya penyimpangan tumbuh kembang. Gangguan tumbuh kembang ini dapat menyebabkan hambatan dan proses belajar disekolah, yang menunjukkan berbagai tingkah laku yaitu malas untuk menulis, kurangnya minat belajar, dan berpengaruh juga terhadap kepribadian anak diantaranya anak akan merasa rendah diri dan sering khawatir mengahadapi lingkungannya (Suryanto S, 2014).

Tumbuh kembang balita memerlukan rangsangan/stimulasi yang digunakan untuk menumbuhkan potensi pertumbuhan dan perkembangan. kehidupan fisik, meningkatkan kesehatan anak, dan fasilitator bagi anak agar dapat mengembangkan kemampuannya. Beberapa studi menunjukkan bahwa anak yang mendapatkan stimulasi secara teratur dan penuh kasih sayang akan dapat mengendalikan dan mengkoordinasikan otot-ototnya melibatkan perasaan emosi serta pikiran sehingga pertumbuhan dan perkembangan anak dapat berjalan optimal. Faktor yang mempengaruhi kepatuhan orangtua dalam melakukan stimulasi yaitu orangtua yang sibuk bekerja, kurang memiliki waktu, bahkan kurangnya pengetahuan tentang stimulasi tumbuh kembang.

Metode stimulasi yang dilakukan selama ini masih mengandalkan tenaga kesehatan yang dilakukan sebulan sekali diposyandu. Namun, hingga saat ini gangguan tumbuh kembang yang disebebkan kurangnya stimulasi masih manjadi masalah. Gangguan tumbuh kembang yang berupa penyimpangan pertumbuhan, penyimpangan perkembangan serta penyimpangan mental emosional, misalnya sindrom 
down, perawakan pendek, dan gangguan autism dapat terjadi salahsatunya karena faktor kurangnya pengetahuan dan ketrampilan orang tua tentang deteksi dini tumbuh kembang ((Suryanto S, 2014).

Di era informatika seperti saat ini dimana teknologi semakin berkembang pesat seharusnya informasi tentang stimulasi tumbuh kembang anak bukanlah hal yang sulit untuk diperoleh, dibutuhkan sebuah sistem informasi yang mudah dan praktis yang dapat dibuka setiap saat untuk mendapatkan informasi terkait tumbuh kembang anak. Sarana pendidikan kesehatan yang dapat digunakan diantaranya adalah media elektronik. Perkembangan tekhnologi informasi pada perangkat bergerak saat ini berkembang cepat, hal ini dapat menjadi salah satu sarana bagi ibu untuk bertukar informasi. Media yang dapat digunakan dalam meningkatkan pendidikan kesehatan yaitu penggunaan smartphone. Smartphone memiliki tambahan aplikasi Personal Digital Assistant (PDA), internet akses, pesan singkat, penerima email, dan lain-lain (Jaranit, 2010).

Klansja dan Pratt menyebutkan bahwa samrtphone efektif dalam pelayanan kesehatan karena penggunaan yang luas, mudah dibawa dan dapat menyajikan informasi secara pribadi (Klansja, 2012).

Peneliti sebelumnya telah membuat aplikasi stimulasi tumbuh kembang balita yang terdapat di smartphone yang diharapkan berfungsi sebagai panduan orangtua melakukan stimulasi terhadap anaknya.

\section{METODE PENELITIAN}

Penelitian ini merupakan jenis penelitian kuantitatif yang menggunakan rancangan pre eksperimen dengan teknik one group pre post design. Populasi terdiri dari ibu yang mempunyai anak berusia $9-60$ bulan dan berdomisili di wilayah Kelurahan Margadana Kota Tegal. Teknik pengambilan sampel akan dilakukan dengan accidental sampling yaitu suatu tipe sampling dimana peneliti dalam memilih sampel yang kebetulan ada. Pengambilan sampel dilakukan selama satu bulan. Instrumen yang digunakan yaitu kuesioner. Analisis univariat data kuantitatif dalam penelitian ini ditunjukkan dengan menerangkan angka atau nilai jumlah masing - masing variabel dengan ukuran persentase. Analisis bivariat dalam penelitian ini digunakan untuk menganalisis perbedaan antara sebelum dan setelah menggunakan 
aplikasi tumbuh kembang balita. Uji Chi

Kuadrat digunakan untuk analisis

bivariabel (Sopiyudin, 2011).

\section{HASIL DAN PEMBAHASAN}

Tabel 1. Karakteristk Responden

\begin{tabular}{ll}
\hline \multicolumn{1}{c}{ Karakteristik } & \multicolumn{1}{c}{$\mathbf{F ~ ( \% )}$} \\
\hline Umur & \\
$<20$ tahun & $2(6,7 \%)$ \\
20-35 tahun & $18(60 \%)$ \\
$>35$ tahun & $10(33,3 \%)$ \\
Pendidikan & \\
SD / sederajat & $8(26,7 \%)$ \\
SMP / sederajat & $14(46,7 \%)$ \\
SMA / sederajat & $8(26,7 \%)$ \\
Pekerjaan & \\
Bekerja & $1(3,3 \%$ \\
Tidak bekerja & $29(96,7 \%)$ \\
\hline
\end{tabular}

Dari Tabel 1 diperoleh gambaran bahwa umur responden mayoritas sekitar 20-35 tahun yakni sebanyak 60\%. Dilihat dari tingkat pendidikannya, pendidikan responden paling banyak SMA / sederajat yakni sebanyak $46 \%$ dan dilihat dari pekerjaannya, mayoritas responden yakni sebanyak 96,7\% tidak bekerja.

Tabel 2. Efektivitas (Isi, Bentuk, Kemudahan Penggunaan, Keakuratan, Ketepatan Waktu) Aplikasi Tumbuh Kembang Balita Pada Ibu Balita Usia 9 - 60 Bulan Di Kelurahan Margadana Kota Tegal

\begin{tabular}{|c|c|c|c|c|c|}
\hline \multirow{2}{*}{ Indikator Efektifitas } & \multirow{2}{*}{$\begin{array}{c}\text { Pre test } \\
\mathrm{N} \\
\end{array}$} & \multicolumn{3}{|c|}{ Post test } & \multirow{2}{*}{ Nilai $p$} \\
\hline & & $\%$ & $\mathbf{N}$ & $\%$ & \\
\hline \multicolumn{6}{|l|}{ Isi } \\
\hline Sesuai & 28 & 93,3 & 28 & 93,3 & \multirow{2}{*}{$\mathbf{0 , 1 2 2}$} \\
\hline Tidak sesuai & 2 & 6,7 & 2 & 6,7 & \\
\hline \multicolumn{6}{|l|}{ Keakuratan } \\
\hline Akurat & 25 & 83,3 & 27 & 90 & \multirow{2}{*}{$\mathbf{0 , 4 3 2}$} \\
\hline Tidak Akurat & 5 & 16,7 & 3 & 10 & \\
\hline \multicolumn{6}{|l|}{ Bentuk } \\
\hline Bagus & 18 & 60 & 18 & 60 & \multirow{2}{*}{$\mathbf{0 , 0 1 4 *}$} \\
\hline Kurang Bagus & 12 & 40 & 12 & 40 & \\
\hline \multicolumn{6}{|l|}{ Kemudahan Penggunaan } \\
\hline Mudah & 24 & 80 & 28 & 93,3 & \multirow{2}{*}{$\mathbf{0 , 0 0 2} *$} \\
\hline Sulit & 6 & 20 & 2 & 6,7 & \\
\hline \multicolumn{6}{|l|}{ Ketepatan Waktu } \\
\hline Cepat & 27 & 90 & 27 & 90 & \multirow{2}{*}{$0,000 *$} \\
\hline Lambat & 3 & 10 & 3 & 10 & \\
\hline
\end{tabular}

Berdasarkan Tabel 2, diperoleh hasil bahwa kelima dimensi efektivitas menunjukkan terjadi peningkatan kepuasan responden setelah menggunakan aplikasi, secara rinci dihasilkan bahwa penggunaan aplikasi tumbuh kembang balita terdapat keefektian yaitu dari segi bentuk 
(format), Kemudahan Penggunaan (Timelines) dan ketepatan waktu (ease of use) dengan hasil uji Chi Kuadrat 0,000 untuk segi ketepatan waktu, 0,014 untuk segi bentuk dan 0,002 untuk segi penggunaan. Penggunaan aplikasi tumbuh kembang balita berpengaruh dari segi isi (content) dan keakuratan (accuracy) dimana dari hasil analisis uji Chi Kuadrat diperoleh nilai-p sebesar 0,432 untuk segi keakuratan dan 0,122 untuk segi isi.

Berdasarkan hasil penelitian menunjukkan bahwa penggunaan aplikasi tumbuh kembang balita terdapat keefektian yaitu dari segi bentuk (format), Kemudahan Penggunaan (Timelines) dan ketepatan waktu (ease of use) dengan hasil uji Chi Kuadrat 0,000 untuk segi ketepatan waktu, 0,014 untuk segi bentuk dan 0,002 untuk segi penggunaan. Penggunaan aplikasi tumbuh kembang balita tidak memberikan kepuasan dari segi isi (content) dan keakuratan (accuracy) dimana dari hasil analisis uji Chi Kuadrat diperoleh nilai-p sebesar 0,432 untuk segi keakuratan dan 0,122 untuk segi isi.

Aplikasi dari segi bentuk, kemudahan penggunaan dan ketepatan waktu sesuai dengan yang dikemukakan oleh Doll dan Torkzadeh bahwa kepuasan pengguna dari sisi tampilan dan estetika dari antar muka sistem diukur dari segi bentuk, format dari laporan atau informasi yang dihasilkan oleh sistem apakah antarmuka dari sistem itu menarik dan apakah tampilan dari sistem memudahkan pengguna ketika menggunakan sistem sehingga secara tidak langsung dapat berpengaruh terhadap tingkat efektifitas dari pengguna. Menurut Doll dan Torkzadeh bahwa Ease of Use mengukur kepuasan pengguna dari sisi kemudah pengguna atau user friendly dalam menggunakan sistem seperti proses memasukkan data, mengolah data dan mencari informasi yang dibutuhkan. Timeliness mengukur kepuasan pengguna dari sisi ketepatan waktu sistem dalam menyajikan atau menyediakan data dan informasi yang dibutuhkan oleh pengguna. Sistem yang tepat waktu dapat dikategorikan sebagai sistem real-time, halini menunjukkan bahwainformasi yang disajikan dalamaplikasi masih belum secara cepat dan efektif sesuai dengan kebutuhan pengguna (Yusuf S, 2014).

Dari segi isi hasil penelitian tidak sesuai dengan yang dikemukakan oleh Doll dan Torkzadeh bahwa Isi dari aplikasi dapat memberikan informasi pada pengguna aplikasi. Dimensi isi juga 
mengukur apakah aplikasi memberikan informasi yang dibutuhkan oleh pengguna. Tingkat kepuasan dari pengguna akan semakin tinggi jika sistem memberikan informasi secara informatif dan lengkap.

Hasil penelitian juga belum sesuai dengan dengan harapan dan pernyataan yang di kemukakan oleh Doll dan Torkzadeh yang menyebutkan Accuracy menilai kepuasan dari sisi keakuratan, instruksi atau arahan yang diterima oleh pengguna aplikasi. Keakuratan sistem diukur dengan melihat sesering apakah informasi tidak memberikan arahan yang tepat sesuai dengan kebutuhan pengguna aplikasi. Adanya ketidak sesuaian ini mungkin disebabkan karena responden menganggap informasi yang ada didalam aplikasi juga terdapat dalam buku - buku panduan yang mereka gunakan.

\section{SIMPULAN DAN SARAN}

Kesimpulan dari penelitian yaitu mayoritas responden berusia reproduksi (20 - 35 tahun), sebagian besar responden tidak bekerja dan berpendidikan SMA, Aplikasi tumbuh kembang balita efektif dari segi bentuk, kemudahan penggunaan dan ketepatan waktu, Aplikasi tumbuh kembang balita tidak efektif dari segi isi dan keakuratan.
Saran diberikan pada bidan dan tenaga kesehatan lainnya agar dapat memberikan pengetahuan yang lebih kepada para ibu bagaimana cara melakukan deteksi dini tumbuh kembang dengan menggunakan metode-metode yang lebih modern sesuai dengan kemampuan ibu balita/ masyarakat. Untuk masyarakat masyarakat hasil penelitian diharapkan dapat menambah wawasan, pengetahuan serta meningkatkan keterampilan bagi masyarakat khususnya ibu yang mempunya anak usia $9-60$ bulan.

\section{DAFTAR PUSTAKA}

Kementrian Kesehatan RI, IDAI, 2016, Deteksi dan Intervensi Dini Tumbuh Kembang Balita, Jakarta: Kementrian Kesehatan RI.

Alimul, A., 2005, Pengantar Ilmu Keperawatan Anak I, Jakarta: Salemba Medika.

Arief, 2010, Deteksi Dini Tanda dan Gejala Penyimpangan Pertumbuhan dan Perkembangan Anak.

Jaranit Kaewkungwal, et al, Application of smart phone in "Better border

health care program": A module for mother and child care. Biomedical and Public Health Informatics, 2010. 10(68): p. 12

Klansja, P., Pratt, W., 2012, Methodological review: Healthcare in the pocket: mapping the space of mobile phone health interventions. Journal of Biomedical Informatics 45(1). 
134 Oksitosin: Jurnal Ilmiah Kebidanan, Vol. 6, No. 2, Agustus 2019 : 127-134

Soetjiningsih., 1995, Tumbuh Kembang Anak, Jakarta: EGC.

Windasari, I.P., Yana, R.R., Aplikasi Mobile Kartu Menuju Sehat (MKMS), Journal Sistem Komputer 6(2).pp 80-83

Suryanto, S., Purwandari, H., Mulyono, WA., 2014, Dukungan Keluarga dan Sosial dalam Pertumbuhan dan Perkembangan Personal Sosial, Bahasa dan Motorik pada Balita di Kabupaten Banyumas, Journal Kesehatan Masyarakat 10(1).pp 103-109.

Sopiyudin D . 2011. Statistik untuk kedokteran dan kesehatan. Jakarta: Sagung Seto.

Yusuf Sutanto, Wing Wahyu Winarno, and Andi Sunyoto, Analisis kepuasan user terhadap website Adi Unggul Bhirawa Surakarta. Informatika, 2014. 1(2): p. 3 